Article

\title{
Driven by Expertise and Insulation? The Autonomy of European Regulatory Agencies
}

\author{
Christoph Ossege ${ }^{1,2}$ \\ ${ }^{1}$ SSM Policy \& Coordination Unit, Federal Financial Supervisory Authority (Bundesanstalt für \\ Finanzdienstleistungsaufsicht), 53117 Bonn, Germany \\ ${ }^{2}$ Bremen International Graduate School of Social Sciences (BIGSSS), Bremen University, 28334 Bremen, Germany; \\ E-Mail: cossege@bigsss-bremen.de
}

Submitted: 26 May 2015 | In Revised Form: 9 February 2015 | Accepted: 19 February 2015 |

Published: 31 March 2015

\begin{abstract}
Expertise and autonomy are cornerstones to the effective operation and legitimacy of European Regulatory Agencies (ERAs). Yet, we know little about ERAs' actual autonomy, nor about factors shaping it. This article studies ERAs' actual autonomy from public and private actors, emphasising two crucial explanatory factors: expertise and rulemaking competences. The lack of insights on expertise is particularly striking, as expertise-the "raison d'être" and main resource of expert bodies-provides ERAs with a potentially powerful means to increase autonomy. Relying on a rational institutionalist framework within which ERAs enjoy substantive discretion to pursue their goals, the study empirically compares three powerful ERAs - the European Medicines Agency, the European Chemicals Agency, and the European Food Safety Authority. Based on the analysis of 39 semi-structured expert interviews, findings show that expertise is a crucial explanation for ERAs' substantive autonomy from the Commission. Towards research intensive private stakeholders, the role of expertise becomes less pronounced. Instead, ERAs are more successful in protecting their autonomy by engaging in the risk-averse interpretation of the regulatory framework and by adapting rules over time to adapt their needs: they engage in "procedural insulation". Political salience provides a scope condition for ERAs to use expert knowledge and rulemaking competences more strategically-potentially undermining scientific quality.
\end{abstract}

\section{Keywords}

autonomy; delegation; EU agencies; EU governance; expert advice; expertise; insulation; regulation; rulemaking

\section{Issue}

This article is part of the special issue "The Role of Expert Knowledge in EU Executive Institutions", edited by Professor Åse Gornitzka (University of Oslo, Norway) and Dr. Cathrine Holst (University of Oslo, Norway).

(C) 2015 by the author; licensee Cogitatio (Lisbon, Portugal). This article is licensed under a Creative Commons Attribution 4.0 International License (CC BY).

\section{Introduction}

European Regulatory Agencies (ERAs) have become increasingly important features in the European polity, regulating many areas of daily life. Forming part of a global rise of expert bodies, ERAs are expected to cope more effectively with complex socio-economic challenges and to overcome political short-sightedness. Their scientific expertise and their autonomy from external influence form the two building blocks for the high-quality decision-making of ERAs-and hence their effective operation and legitimacy (Majone, 2009). Expertise means accurate information that can be put to adequate use by "experts". Autonomy refers to the degree to which an agency can actually take decisions irrespective of external actors' preferences.

Although expertise and autonomy are deemed central to the operation of ERAs, their specific contribution to the functioning of ERAs remains unclear in many respects. In fact, many facets of ERAs' day-to-day operation remain in the dark (Groenleer, 2014). When explaining the autonomy of ERAs, two-so far neglected- 
factors seem particularly worthwhile to study: an agency's expertise and its rulemaking competences. Expertise "substitutes power in certain policy areas" (Quaglia, 2009, p. 13), potentially forming a "key prerequisite for bureaucratic autonomy" (Carpenter, 2001, p. 17). As expert organisations, ERAs are particularly likely to capitalise on their expert resources. In addition, ERAs' extensive soft-law rulemaking competences enable them to modify existing - and introduce newregulatory rules. Therewith, ERAs could insulate themselves by actively raising procedural standards. Although Moe (1995) regards these expertise- and rulebased explanations pivotal to the autonomy of ERAs, they lack systematic scholarly attention. Accordingly, the research question is:

How (and under what conditions) can ERAs capitalise on their expertise and rulemaking competences to "forge" their autonomy?

Analytically, the project builds on an institutionalist framework within which ERAs are equipped with the necessary room of manoeuvre to pursue their goals and interests. Reflecting recent insights on "knowledge utilisation", the ability (and necessity) of ERAs to shape their autonomy depends on an important scope condition: the political salience of the regulatory issue at stake (Boswell, 2008). Providing concise expectations on agency autonomy to guide the empirical analysis, the framework explicitly distinguishes between the political principals - centrally the European Commissionand private stakeholders of ERAs. The different nature of their relationships with ERAs is expected to shape agency autonomy in different ways.

Empirically drawing on original expert interviews with agency staff and external actors, the study provides unique comparative insights on the autonomy and day-to-day operation of three powerful ERAs: the European Medicines Agency (EMA), the European Food Safety Authority (EFSA), and the European Chemicals Agency (ECHA). Given their technical mandates, these ERAs are particularly well suited to study the postulated relationships between expertise and autonomy ("most-likely-cases").

After introducing the general debate on ERAs, the analytical framework develops the expectations concerning the effects of expertise and rulemaking competences on the autonomy. Following a short methodological note, introducing the selected ERAs, the empirical analysis first shows whether expertise holds its promise to protect agency autonomy. In a second step, the study assesses whether ERAs are able to capitalize on (the interpretation and modification of) the regulatory framework, therewith engaging in procedural insulation. The study concludes by linking findings to recent debates on agency operation and their role in EU governance.

\subsection{Regulation by Information: Autonomy and Expertise of ERAs}

Reflecting a global "rise of the unelected", the EU can be depicted as a fore-runner of expert governance (Curtin, 2014; Vibert, 2007). Next to comitology committees and other forms of network governance for expert advice (Sabel \& Zeitlin, 2008), the European decision makers rely on the expert advice of so-called European Regulatory Agencies (ERAs). Forming part of a greater population of EU agencies, eleven such ERAs exist and are primarily concerned-as their name suggests-with regulation. Functionally disaggregated from political decision-making processes, ERAs form the most consistent institutional example of autonomous expert advice in the EU (Busuioc \& Groenleer, 2014). Accordingly, expertise and autonomy form the two operational cornerstones of ERAs.

Since ERAs ought to provide policy makers with sound expert advice, the expertise to inform this advice constitutes their main organisational resource. The (scientific) expertise ${ }^{1}$ provided by ERAs does not only have to concord to abstract scientific standards. Commonly referred to as "regulatory science", ERAs' expertise has to turn into serviceable "truth" by being timely and useful (Lentsch \& Weingart, 2011, p. 9). ${ }^{2}$ Directly feeding into policy-making, it is particularly "susceptible to divergent, socially conditioned interpretations...since quality standards tend to be more fluid, controversial, and subject to political considerations" (Jasanoff, 1995, p. 282). In this vein, the expertise of ERAs is neither "neutral, objective, [nor] technically virtuous" (Shapiro \& Guston, 2007, p. 543). A central reason for divergent expert interpretations lies in the recognition that expertise is always linked to (groups of) "experts" or professionals (Radaelli, 1995). They form part of professional communities (Noordegraaf, 2007, p. 767), often referred to as "epistemic communities", sharing sets of "causal beliefs and common notions of validity" (Haas, 1992, p. 2; Davis Cross, 2012). Within and across these expert communities, scientific controversies "can arise out of "honest philosophical differences' linked to disciplinary training, institutional affiliation, or professional status" (Jasanoff, 1995, p. 281; see also Joerges, Ladeur, \& Vos, 1997). ${ }^{3}$ Nonetheless, expert knowledge can be put to scrutiny regarding its reasoned arguments based on substantive and methodological standards (Brown, 2009, p. 202).

\footnotetext{
1 The terms "expertise", "scientific expertise" or "expert knowledge" are used interchangeably-if not explicitly stated otherwise.

2 Other authors speak of "trans-science" or "mode-2 science" (for an overview, see Lentsch \& Weingart (2011)).

3 Prospect theory provides empirical evidence that experts rely on different "heuristics" to interpret the same information (Tversky \& Kahnemann, 1992).
} 
Autonomy refers to the degree of freedom that ERAs experience when they take decisions "relatively unbound by the preferences and interests" of external actors (Groenleer, 2014, p. 258). At the same time, an autonomous agency is not required to operate in isolation, as external expert advice might often contribute to ERA's prescribed goals. One should distinguish between formal and de-facto autonomy. Formal autonomy describes an agency's discretion to act or make decisions as defined in its founding regulation (Carpenter, 2001). Four dimensions are often identified: legal, financial, personnel, and policy autonomy.

This article is interested in the policy autonomy of ERAs. Whereas all EU agencies are independent legal entities-and thus legally autonomous-, their formal autonomy to take policy decisions is often said to be limited (Groenleer 2009, 2014): in fact, all EU agencies-including the ERAs studied in this article-are deprived of formal policy-making competences. Although their scientific opinions form the basis for risk regulation in the $\mathrm{EU}$, the binding regulatory decisions reside with the Commission and the respective Standing Committees; often jointly referred to as the "risk managers" (Busuioc, 2013). Since Carpenter (2001, p. 5) argues that autonomy is quintessentially about "independent policymaking power", this lack of formal decision-making powers led scholars to argue that ERAs' policy autonomy is considerably circumscribed. This study, however, draws an explicit distinction between policy autonomy and policy influence (Maggetti, 2009): if ERAs take a decision unbound by external interests, they will experience high degrees of autonomy. Whether this decision is then adopted by the risk managers does not affect the autonomy of ERAs but rather concerns the agency's policy influence-lying outside of the scope of this article.

In any case, an agency's formal (policy) autonomy does not automatically translate into actual or de facto autonomy (Carpenter, 2001; Olsen, 2009). Once an agency is created, its actual autonomy might change over time: Reflecting neo-institutional thought, the autonomy of expert bodies is shaped by-but not limited to the effects of-legal and organisational factors (Rittberger \& Wonka, 2011). Despite the illustrated importance of reputation-building and institutionalisation (Carpenter, 2001; Groenleer, 2009), however, we lack systematic insights on the actual policy autonomy of ERAs (Egeberg \& Trondal, 2011). Therefore, this article studies the de facto autonomy of ERAs in developing their main policy output: their risk assessments.

Expertise and rulemaking competences provide two-so far neglected-explanations for this autonomy. With the recent exception of a "knowledge utilisation" study (Boswell, 2008), general claims of the importance of expertise in policy-making have not been complemented by systematic empirical analyses (Quaglia, 2009; Radaelli, 1995). We also lack infor- mation on the ability of ERAs to capitalise on their rulemaking competences to protect their autonomy (Kaufman, 2001). ERAs are particularly well-suited to study the above-question, as they closely interact with scientific and advocacy actors within so-called regulatory networks. The network interactions with regulators and expert bodies contribute to agency expertise and thus regulatory quality. This study assumes that the expert bodies of these networks pose no harm to the autonomy of ERAs, since they operate in line with the "logic of science" (Davis Cross, 2012).

The regulatory networks, however, also provide socalled advocacy actors with direct access to decision makers (Braun, 2012). The public actors (the European Commission, the Member States, the European Council and the European Parliament) can be considered "principals" of ERAs. Private advocacy actors include industry companies (and federations) as well as nongovernmental organisations (NGOs). Existing research shows that advocacy actors strive to impose their own preferences onto ERAs, potentially threatening their autonomous decision-making (Groenleer, 2009). The network involvement of ERAs therefore serves as a potential catalyst both to the generation of expert knowledge and to threats on autonomy.

Due to the observed limited role of the European Parliament, the European Council and Member States for ERA decision-making (Groenleer, 2009), this study focuses on the autonomy of ERAs from the Commission as well as private stakeholders. ${ }^{4}$

\section{Analytical Framework}

The project sets out a rational institutional framework to study the behaviour of ERAs. Rational institutionalist theory argues that "EU institutions matter, shaping both the policy process and policy outcomes in predictable ways" (Pollack, 2015, p. 20). Despite the importance of institutions-including formal rules and procedures-, this theoretical approach leaves agents with ample room of manoeuvre to pursue their goals and interests (Olsen, 2007, p. 13).

Within this framework, the article draws on insights from delegation theory and "knowledge utilization": This article identifies the areas of discretion for ERAs to forge their own autonomy; it then develops expectations on how they can use their discretion by capitalizing on (2.1.) their expertise, and (2.2.) their rulemaking competences. Insights on "knowledge utiliza-

\footnotetext{
${ }^{4}$ Member States in particular might nonetheless wield substantive influence on regulatory policy-making in the EU given their membership in Standing Committees. This policy influence, however, does not undermine the autonomy of ERAs. Instead, it is deemed to affect (and potentially undermines) the importance of the agencies' risk assessments in the overall policy-making process.
} 
tion" suggest that (2.3.) the necessity and ability of ERAs to actively "forge" their autonomy-a main goal of any bureaucratic actor-depends on the scope condition of political salience (Boswell, 2008).

\subsection{The Power of Expertise-Asymmetries \& Counter-Expertise}

Established to provide public decision-makers with scientific advice, ERAs are assumed to host high levels of scientific expertise. Delegation literature suggests that the distribution of information is essential to understand the relationship between a principal and an agent (Majone, 2002). Monopolising relevant information provides agents with a powerful means to guard, and even to increase, their discretionary space to take autonomous decisions (Gailmard, 2002; Lavertu $\&$ Weimer, 2009). Since the Commission-arguably the agencies' main principal-delegated risk assessments and transferred a significant share of its experts to ERAs, the Commission itself is expected to hold limited degrees of scientific expertise. The lack of expert capacity among Commission DGs might even threaten their ability to adequately control the quality of agency opinions (Busuioc, 2013). ERAs are therefore expected to benefit from a classical information asymmetry that is sufficient to prevent the Commission from influencing the decision-making of ERAs.

Towards private stakeholders - particularly towards industry-delegation theory provides less explanatory potential, since the relationship between ERAs and stakeholders does not reflect a principal-agent relationship. Rather, industry acts as a client to ERAs. Moreover, one cannot speak of typical information asymmetries benefiting ERAs. In fact, industry might even hold more expertise than ERAs: industrial companies develop the products and substances submitted to ERAs for authorisation and perform the required tests. Regulators rarely engage in empirical experiments themselves but instead rely on data provided by private applicants.

Nonetheless, the resource-based reasoning adequately describes the relationship between ERAs and private stakeholders. Holding high-quality expert resources themselves, ERAs might be in a position to (a) question scientific arguments put forward by industry and potentially develop counter-expertise. ERAs can also (b) identify and dismiss non-scientific arguments that go beyond the decision-making criteria specified in the agency regulations and guidelines. Even though information asymmetries are unlikely to materialise, ERAs are therefore expected to hold sufficient expert resources to fence off external influence by industry and NGOs. Although to varying degrees, the scientific expertise of ERAs might therefore protect them effectively from external influence from the Commission and private actors.
Expectation 1a: Information asymmetries towards the Commission provide ERAs with high degrees of autonomy.

Expectation 1b: ERAs hold sufficient scientific expertise to counter scientific claims by private stakeholders, therewith protecting their autonomy.

One should bear in mind that the relationship between expertise and autonomy is not unidirectional. Both concepts might be linked in an interdependence model: While expertise is expected to increase autonomy, autonomy might also contribute to expertise (by increasing the reputation, attracting high-level scientists). This study restricts itself to the ways in which expertise contributes to autonomy.

\subsection{The Regulatory Framework \& Procedural Insulation}

The effects of expertise are complemented by a process of procedural insulation that potentially increases agency autonomy from private stakeholders. Since the Commission has established the regulatory framework governing the operation of ERAs and acts as "guardian of the treaties", it casts a legal "shadow of hierarchy" onto agency rulemaking. Accordingly, procedural insulation serves ERAs to protect their autonomy towards private stakeholders. While extensive regulatory provisions (guidelines and procedures, test methods, time frames for the assessment process) restrict the behaviour of ERAs, they simultaneously limit the access points of external actors, protecting ERAs' autonomy (Gehring \& Krapohl, 2007). Kaufman (2001, p. 34) observes that "red tape to one person may be a treasured procedural protection to another".

At the same time, however, the regulatory framework is far from static. Regulatory rules require interpretations and many ask for modifications once an ERA has gained more experience in implementing the regulatory framework. Within the larger legal framework set by the European institutions, ERAs moreover hold substantive "soft-law" rulemaking competences (Chiti, 2013). By (re)interpreting and modifying existing rules and introducing new ones, ERAs can effectively raise regulatory standards, for instance by altering the scientific information required for a product authorisation. These regulatory changes might significantly improve the quality of the regulatory output. At the same time, however, the changes could limit the ability of external actors to influence the decision-making of ERAs (Moe, 1995).

E2: By engaging in "procedural insulation", ERAs can increase their level of autonomy from private stakeholders.

\subsection{Political Salience as a Scope Condition}

The effectiveness of ERAs' means to protect their au- 
tonomy hinges on the scope condition of political salience. Salient issues are those with a broad scope and intensity of conflicts, either for economic or political reasons (Gormley, 1986, p. 598). Since highly salient issues involve high stakes, external actors are believed to increase their efforts to influence agency decisionmaking. This increased external pressure might (partly) undermine the ability of ERAs to guard their autonomy via the means specified above.

E3: High political salience alters the means of ERAs to guard their autonomy.

Concerning the autonomy of ERAs, two scenarios are viable:

a. If the conditioning effect of political salience were applicable, one could expect ERAs to experience lower degrees of autonomy in areas of high political salience (E3a).

b. In face of highly salient issues, however, ERAs might also strategically adapt their behaviour to the changed circumstances. Rather than engaging in "instrumental problem solving, ERAs could make strategic use of their expertise and/or rulemaking competences with the primary goal of protecting their autonomy (Boswell, 2008; Schrefler, 2010). This change in behaviour could guard ERAs" high degrees of autonomy-even in areas of high political salience (E3b).

To assess the relevance of political salience as a scope condition, this project studies regulatory issues of both high and low salience. This approach sheds light on the reach of the study's main expectations. Presumably, salience does not systematically vary across ERAs, but rather across issue areas.

\section{A Methodological Note-Comparing EMA, EFSA, and ECHA}

Guided by theoretically informed expectations, the study remains exploratory. Comparing three ERAs provides an adequate balance between the necessary analytical leverage to assess general expectations, and a desirable level of detail.

Although EMA, EFSA, and ECHA differ in certain regards, their extensive similarities recommend them for a comparative study on agency autonomy. Created for different reasons at different points in time, they nonetheless share important organisational and functional traits (Groenleer, 2014): all three ERAs hold similar mandates, as they serve as gatekeepers for products to enter the respective markets and evaluate products and substances already available-potentially withdrawing the marketing permits (Vos, 2014, p. 20). Given their scientific tasks, the selected ERAs are most likely to capitalise on available expertise to protect their autonomy. Despite minor variations, all three ERAs experience high degrees of formal autonomy, setting them apart from other ERAs-often equipped with less formal autonomy. Although deprived of formal decision-making competences, all three ERAs are moreover perceived of as "de-facto" decision-makers in the EU (Busuioc, 2013, p. 211). Findings on thesearguably most powerful-ERAs therefore provide most instructive insights on EU policy-making. Moreover, all three ERAs operate in a similar environment (industry structure, stakeholder activities). As Groenleer (2014, p. 265) argues, the (limited) observable differences across regulatory domains do not "explain a difference in agency autonomy". Finally, alternative explanatory factors linked to the agencies' organisational structure are controlled for: all three ERAs come in similar sizes and shapes, being composed of an agency secretariat, scientific committees, and a management board. At the same time, the cases provide the necessary internal and cross-case variation concerning their de facto autonomy, as pointed out by Groenleer concerning EMA and EFSA (2009, 2014). Their (use of) expertise is also expected to differ.

The analysis rests on 39 semi-structured expert interviews with agency members and external actors (ERA Secretariats, Scientific Committees, Management Boards; EU Commission, EU Parliament, NGOs, industry federations), providing detailed insights on day-to-day processes related to agency decision-making and autonomy. ${ }^{5}$ The (perceptional) interview statements on the main concepts were coded according to a preestablished coding scheme (i.e., "high/medium/low autonomy"). Coding was based on general perceptions of interviewees on agency operation, and references to specific instances of (non-)influence, refering to e.g. authorisation procedures where stakeholders (are perceived to) have successfully altered an agency's opinion. This approach is complemented by extensive narrative quotes. Potential biases inherent to interview data, i.e., overestimation of expertise or autonomy, are accounted for by (a) the systematic selection of interviewees, and (b) the triangulation of interview data with documents, more specifically annual agency reports and external evaluations conducted on all three ERAs.

\section{Analysis}

Despite the frequent interactions between all three ERAs and external actors, the interview data suggests that all three ERAs under study experience high degrees of autonomy from external actors:

\footnotetext{
${ }^{5}$ Ossege (forthcoming) provides more details on the selection of interviewees.
} 
Scientifically, yes. I would say that the scientific outputs are not at any level influenced by DG SANCO views or by the EP views or by stakeholder views. I think, scientifically, it is really independent. But of course, economically and at the management level it has boundaries and it has a lot of links with others. But that doesn't affect the scientific outputs. (EFSA3)

38 out of 39 interviewees share this perception, while one interviewee observes industry influence in EFSA's regulation of genetically modified organisms (EFSA$\mathrm{GMO}$ ). At the same time, two interviewees dealing with ECHA raise tangible criticism on the chemicals agency, claiming that the agency's proximity to industry threatens to affect its decision-making:

If you look at what experts they are getting from particular disciplines, etc. and how many from industry or from academia, how many are coming from Germany with a huge chemical industry, and you can foresee a certain amount of industry cosiness. I don't have any figures, but I have the impression that many industry friendly people are working for ECHA-I can't prove it. (ECHA-NGO; similar: ECHA-COM)

Assuming the validity of interview statements, these challenges-although pointing at a potential threatdo not undermine the observed high levels of autonomy of all three ERAs.

\subsection{The Role of Scientific Expertise-Asymmetries and Counter Expertise}

ERAs' extensive expertise-generated inter alia through the involvement of experts (from NCAs and other expert bodies) into their decision-making bodiesprovides a strong explanation for autonomy. The effects of this high quality expertise on autonomy play out differently towards the European Commission and private stakeholders.

\subsubsection{Asymmetries towards the Principal}

The Directorate Generals (DGs) in the Commission extensively interact with the ERAs at the scientific and the management level, both formally and informally (ECHA-COM). Nevertheless, the DGs are perceived to have little influence on the agencies' decisions. While the Commission has an observer status in the committees of each agency, its representatives do not take active part in the discussions. As one interviewee involved in an ECHA committee recalls her experience (ECHA8): "The Commission is sitting in the committee as an observer, they can contribute to the discussion, if they want to. But I do not recall that they said any- thing". This perception is shared by the other interviewees involved in the committee work, across agencies. ${ }^{6}$

The limited scientific expertise of Commission representatives provides a main explanation for their low influence on ERA decision-making:

It can happen that the people in the Commission do not understand the opinion and then they follow up with questions. But the Commission completely lacks the potential and scientific foundation.... (EMA1)

I do not think they have a lot of scientific expertise. They never had. They are policy makers. Of course they have scientists working there, and they have lawyers working there, but the lawyers do not deal with individual decisions and the scientists are not supposed to be...I mean the Commission has outsourced this sort of questions to the agencies, that is why they established agencies.... They only need to keep the level of expertise that they can understand what is coming and to be properly informed so that they can make the decision. (ECHA1)

While the Commission lacks the expertise to influence ERA decision-making, it nonetheless holds enough knowledge to follow the latter's argumentation:

And so [the Commission representatives] have of course their expertise, but now of course with the more defined roles of different actors we are the body that is supposed to be the technical and scientific body, really having the in-depth scientific expertise; and they are more deeply into the policy and regulatory level so that there is not too much overlap. But of course, also we have to understand each other and therefore they have relevant expertise for us, and we are consulting with them on issues. (ECHA7)

If DGs get involved into specific risk assessments, they want to be aware of potentially conflicting scientific arguments put forward in the debate before they have to deal with them (and potentially defend them) in later phases of the policy process and in the court room (EMA7; ECHA-COM). Particularly due to this fear of litigation shared by (all three) ERAs and the Commission, some interviewees attribute a slightly more influential role to the Commission (ECHA1, ECHA-COM, EMAFederation). Overall, however, the Commission's sphere of influence is limited to making sure that the decisionmaking is in line with legal requirements. This high degree of autonomy from the Commission even holds true for EMA, although it has experienced a substantive

\footnotetext{
${ }^{6}$ Similar statements are advanced by EMA6, EMA7; EFSA1, EFSA2, EFSA3 EFSA8; ECHA1, ECHA7, ECHA8, ECHA-RAC.
} 
surge in oversight since 2010, when DG SANCO replaced DG INDUSTRY as the agency's partner-DG. While the greater organisational duplication between the DG SAN$\mathrm{CO}$ and EMA triggered closer scientific involvement of the DG (EMA-Federation), the increased influence appears limited to legal concerns (Vestlund, 2014).

With their regulatory oversight role, the DGs primarily contribute to the regulatory consistency of the agencies' output. In line with expectation E1a, they lack the scientific expert knowledge to intervene on the decision-making. If they engage in expertise-based discussions, it rather appears like a knowledge transfer from ERAs to the Commission. Accordingly, the lack of expertise among Commission DGs appears to be sufficient to prevent them from directly influencing ERAs in their assessment work (asserting E1a).

\subsubsection{Counter-Expertise towards Private Stakeholders}

Private stakeholders provide a different picture. As argued above, ERAs remain rather autonomous in their decision-making despite the intensity of interactions between ERAs and private stakeholders. Contrary to the relationship to the Commission, however, this autonomy from private stakeholders, industry in particular, does not stem from a traditional information asymmetry. Industry companies heavily invest in research and development, attract highly skilled experts, accumulating top-level expertise (ECHA-NGO, EFSA-NGO).

Nonetheless, all three ERAs hold sufficient expertise to counter external claims, for instance by uncovering rather frequent flaws in application dossiers submitted by industry. While flawed dossiers are submitted to all three agencies, the respective evaluation reports suggest that the recently established ECHA is most affected (PricewaterhouseCoopers (PwC), 2012). One reason for these flaws lies in stakeholders' lack of experience with (and expertise on) the rather new regulatory procedures governing the regulation of chemicals (ECHA4). But interviewees of all three ERAs also report on deliberate intents to hide "certain things" in application documents (ECHA4), and on companies submitting flawed data (EFSA-GMO). In this vein, EMA regularly request additional information from the applicant, "either to solve the problem in a positive way or to say 'it is better to withdraw the product"' (EMA1). As a consequence, applicants in all three ERAs regularly withdraw their applications before receiving a final (potentially negative) verdict on their application (EMA1, EMA-CHMP, EFSA-GMO, ECHA-MSC1). While EMA and EFSA do not publish the relevant statistics, EMA's annual report (2013) indicates that approximately $14.5 \%$ of the initial market authorisation applications submitted to the Committee for Human Medicinal Products (CHMP) between 2009 and 2011 have been withdrawn prior to a final agency opinion (an additional 5.5\% has received a negative opinion).
Although the interview statements and application data retrieved from EMA do not provide a conclusive picture, they clearly suggest that ERAs hold the necessary expertise to detect flawed arguments advanced by stakeholders $(E 1 b)$. Whereas high quality expertise seems to provide a sufficient explanation for ERAs' autonomy towards the Commission, it provides ERAs with less leverage to protect their autonomy towards private stakeholders.

\subsection{Protection towards Stakeholders-The Static Framework and Procedural Insulation}

The analytical framework suggested that ERAs benefit from a second factor that contributes to the observed high degrees of autonomy from private stakeholders. Specifically, ERAs might capitalise on (a) the extensive regulatory provisions governing their relationship with stakeholders, and (b) the process of procedural insulation.

\subsubsection{The Static Regulatory Framework-Rules as Procedural Protection}

The analysis shows that the extensive regulatory provisions provide ERAs with a legally robust guiding post for action: interviewees depict all three ERAs as highly rule-oriented, "strictly respecting legislation" (ECHAFederation). This risk averse behaviour of following rules "to the letter" - at least partly-aims at avoiding litigation (EMA-Federation; EFSA5, ECHA-COM). While all three ERAs act very rule-oriented, ECHA is characterised as particularly risk-averse:

[ECHA staff] are extremely obsessed with procedures. Sometimes it really drives me mad. I can see partly why they do it, but it gums up the works to some extent. In fact, PwC did a report, they did a workshop here and invited some of us there to discuss. Industry and NGOs agreed that ECHA is very bureaucratic, so that is something we share views on. (ECHA-NGO)

Given ECHA's young history and the subsequent lack of established regulatory practices, ECHA faces considerably more legal uncertainty associated with the regulatory framework than EMA and EFSA (ECHA8; ECHACOM). Gaining experience, however, ECHA appears to act more confidently lately (ECHA1; ECHA-COM; ECHAFederation). Overall, all three ERAs remain highly ruledriven.

Whereas this rule-orientation contributes to autonomous expert advice, EFSA's handling of the nutrition and health claims regulation ${ }^{7}$ suggests that it might al-

\footnotetext{
7 The regulation establishes rules aimed at harmonising nutrition and health claims across Europe. Since the inception of the regulation in 2006, this "claim on food labelling, presentation
} 
so bring about unintended consequences. Overall-and supported by a rejection rate of $80 \%-$ EFSA's evaluation of health claims is widely regarded as highly demanding and scientific (ANH Europe, 2011). At least some rejections, however, go back to a formalistic interpretation of Council Regulation 1924/2006. In one example, EFSA rejected a health claim that "water prevents dehydration", since the provided information on "water loss in tissues" did not qualify as the required "risk factor", but rather as a measure of the disease itself. While legally consistent, this decision might raise substantive concerns. Natural and botanical food ingredients, which have nearly been rejected in their entirety, serve as another illustration (ANH Europe, 2011). While EFSA adheres to the standards prescribed in the regulation in both examples, the agency runs the danger of operating in a vacuum-neglecting potentially redistributive effects of its decisions on entire industries.

The analysis brings another observation to the fore: Many stakeholders lack experience with (and expertise on) the complex regulatory requirements. NGOs even lack the (financial and human) resources to overcome this challenge (ECHA-NGO; EMA-NGO). Among industry, especially small and medium-sized enterprises (SMEs) struggle with the magnitude of formal regulatory requirements. As an industry representative points out, companies working with EMA even have difficulties to understand the role of the individual committees (EMA-Federation). While most industrial companies know certain regulatory aspects, many lack a coherent understanding of the broader regulatory framework and the functioning of the agencies. This reported lack of regulatory understanding among stakeholders circumscribes their ability to influence agency decision-making. Consequently, the complexity of the regulatory framework (without the complementary expertise among stakeholders) contributes to the autonomy of ERAs.

At the same time, the complex framework and the lack of regulatory understanding potentially undermines regulatory quality, as indicated by the substantive amount of flawed applications submitted to the recently established ECHA. All three ERAs have introduced various initiatives to overcome these negative implications through a variety of initiatives, including stakeholder fora to exchange experiences and the establishment of advice-units: EMA created an SME Office in 2005, EFSA and ECHA introduced similar application helpdesks to support applicants. For ERAs, these initiatives provide a double-edged sword: while the improved regulatory understanding of stakeholders contributes to a smooth regulatory process, the increasing number of court cases suggests that it also

and advertising must be clear, concise and based on evidence accepted by the whole scientific community" (Council Regulation 1924/2006; Summary). provides stakeholders with the means to contest agency decision-making and potentially undermine autonomy (Busuioc, 2013).

\subsubsection{Adapting the Rules}

Even if stakeholders improve their understanding of existing regulatory rules, however, ERAs can engage in procedural insulation: "Any actor implementing law needs to interpret law..." (ECHA-MSC2). All three ERAs do not only interpret the current regulatory framework, but they have also modified existing rules and introduced new ones concerning the internal operation of ERAs and their relationship with external stakeholders. Most of these regulatory changes seem to reflect 'instrumental' problem solving to improve the overall regulatory process: detecting deficiencies in the current procedures, ERAs alter these rules to prevent future regulatory failures. As a side-effect, however, external stakeholders face new regulatory challenges that undermine their ability to influence agency decisionmaking, contributing the autonomy of ERAs (E2).

\subsection{High Political Salience: Insulation Turning Strategic}

This observed process of procedural insulation becomes particularly pronounced in areas of high political salience. In salient issues, stakeholders increase their pressure on ERAs (ECHA-RAC). At the same time, ERAs adapt their behaviour accordingly: Aware of the increased external scrutiny, committee members invest additional effort in their deliberations (EFSFA6; ECHARAC). Moreover, all three ERAs engage in procedural insulation more systematically:

[In areas of high salience] we have more leeway. There we have a number of documents which are guidelines, which are supposed to be followed but they are not legally enforceable. So you are not breaking the law if you don't follow them. Many of these guidelines are being drawn up by us. [...we normally] do a good job, but for particular sensitive dossiers we would take extra care, for example in how conclusions of an assessment report are worded, or in making sure that the procedure is followed to the letter. (EMA4)

One gets more careful in formulating opinions, to makes them really clear. But influence on [the panels'] evaluation behaviour rather not, since the criticism is not valid. Where you also become more careful is with public appearances. (EFSA6)

In the following, two examples of procedural insulation serve to exemplify the agencies' awareness of their discretionary space to interpret and modify regulatory rules, and to use this discretion in their favour. 


\section{a) Conflicts of Interest Policies}

Reforms of the policies governing conflicts of interest (Col) provide a prominent example of procedural insulation in all three ERAs. Dealing with a main threat to agency autonomy and applicable beyond individual regulatory procedures, policies governing Col are of high political salience. As a response to major public criticism on their existing Col-regimes, EMA and EFSA have repeatedly introduced more restrictive revisions over the years. Even ECHA, only created in 2006, reformed its initial policy shortly after its creation, mimicking recent changes by EMA and EFSA. All three ERAs intensified the screening of secretariat staff and committee members and raised the applied standards (ECHA, 2011; EFSA, 2011a; EMA, 2012). Observers acknowledge the progress towards protecting the decision-making of ERAs (European Court of Auditors, 2012). At the same time, reforms appear to provide a strategic response ("symbolic action", see Boswell, 2008) to considerable political pressure exerted by the European Parliament, the European Court of Auditors (2012), the European Ombudsman (2013), and NGOs. In addition, reforms show different degrees of success: EFSA in particular still experiences major Col, threatening its autonomy (Horel \& Corporate Europe Observatory, 2013). Interview data suggests that, despite these threats, the autonomy of ERAs remains intact.

Moreover, more restrictive Col policies trigger unintended side-effects, creating difficulties to recruit highlevel experts:

Suddenly all agencies get problems of recruiting experts. You will not find a professor of distinction in pharmaceuticals, who has not in some way, via third party funding, collaborated with industry. Why should he, in the first place? Not everyone, who has collaborated with industry is a criminal....Everyone who exchanges views with industry seems to be a Trojan horse for the detriment of people or public health.... With the result that we have difficulties to recruit experts. (EMA1)

Colleagues from EFSA agree, saying that "every expert naturally has somehow contacts [to industry], otherwise he would not be an expert" (EFSA6). Another interviewee puts it more cautiously: "Still, there is a degree of a problem, also with the internal experts because they have different levels of confidentiality and conflicts of interests. It is an issue, always" (EMA3). The more recently established ECHA does not experience these recruitment challenges, yet.

The analysis shows that Col-policies ought to delineate a fine line: increasingly successful, they ought to protect agency decision-making from external interests. At the same time, however, they should not pose obstacles to the recruitment of high-quality expertise crucial for regulatory work: "one has to manage this tension: you want qualified people, and these sometimes do come from industry" (ECHA-MB).

\section{b) Gallium Arsenide}

Although ECHA's handling of gallium arsenide (GA) provides an extreme case, it forms an illustrative example of how an ERA can protect its decision-making from external pressures by meticulously adhering to procedural standards that might otherwise be applied more flexibly. Used in the micro-electronics industry, GA was classified "category 2" (harmless) by ECHA's Risk Assessment Committee (RAC). Due to novel scientific information provided during the public consultation procedure, however, the RAC revised its assessment and classified GA as highly carcinogenic ("category 1a"). Given the regulatory (and thus economic) implications of this opinion, industry raised major criticism towards ECHA directly, and towards the Commission. Given the acknowledged expert authority of ECHA, industry focused its complaints on procedural concerns: if they had known about the potentially restrictive regulatory action (which was not apparent given the initial proposition "category 2"), they would have contributed differently to the public consultation.

Wary of potential litigation, the Commission requested ECHA to re-evaluate the substance. Flooded with external comments and aware of the close public scrutiny, ECHA became more cautious and invested extra effort to deliver a legally and scientifically sound opinion. Classifying GA as "category $1 b$ ", a committee member acknowledges that this "sounds like a rotten compromise" (ECHA-RAC). He remains confident, however, that the committee worked autonomously from non-scientific influence. Also, category $1 \mathrm{~b}$ leads to similarly burdensome authorisation procedures for industry. Since a final decision on GA is still pending (due to new scientific information provided by industry), the autonomy of this particular decision is difficult to assess. Since the rule-orientation of ECHA and the apparent expertise of committee members kept the scientific essence of the opinion intact during the former revision, the autonomy is assumed to remain high.

As the authorisation of GA illustrates, however, this autonomy might come at a price. Unable to influence the decision-making of ECHA, industry successfully delays potentially restrictive regulatory action: with an eye to other authorisation processes, an ECHA committee member observes that although there is "no direct influence of lobbying pressures [on science], the strategy is clear: re-opening decision-making or keeping it open and therewith eroding the problem" (ECHA-RAC). The obligation of ECHA and other ERAs to respond to each external comment provided during application processes, aimed at assuring the responsiveness of ERAs to novel scientific information, potentially con- 
tributes to these delays as it drains on the organisational resources (EMA6).

Interview statements suggest that similar observations can be made on other processes within ECHA (ECHA-RAC), but also in other ERAs (e.g., EMA6). The continuous reforms of Col policies by all three ERAs in face of major external pressures provide a further example for ERAs' awareness of their discretionary space-and their willingness to make use of it in order to protect their autonomy. The analysis suggests that all three ERAs can use their operational discretion in a similar way: they can interpret and modify existing regulatory rules (at least partly) strategically in order to reduce the chances of legal litigation, effectively guarding their autonomy.

The interview material does not allow to assess whether all three ERAs make always use of this discretion-most likely they do not. In this vein, the authorisation of GA remains an extreme case with limited generalizability. Yet, it illustrates the substantive behavioural discretion that ERAs enjoy-and could make use of-in areas of high political salience. Moreover, interview statements suggest that the observed strategic behaviour is rather common among the three ERAs under study.

\section{Discussion}

The study enhances our limited understanding on the autonomy and operation of ERAs. Despite considerable pressures, the decision-making of all three ERAs appears well protected from both public and private external influence. Whereas other studies have argued that EFSA experiences lower degrees of autonomy than EMA and-more recently-ECHA (Groenleer, 2014), this study observes similarly high degrees of autonomy among all three ERAs. A main explanation for this discrepancy can be found in the more narrow definition of autonomy applied here. Whereas I argue that EFSA enjoys substantive autonomy, its opinions might nonetheless be disregarded by regulatory policy makers. While EFSA therefore experiences high degrees of autonomy, its policy influence is reported elsewhere to be limited (Groenleer, 2014; Ossege, forthcoming). Whereas the distinction between policy autonomy and influence introduced here increases the analytical leverage of the analysis, the nature of their relationship asks for systematic scholarly attention. An agency's inability to shape regulatory outcomes (low influence) might even increase its autonomy: if an ERA's risk assessment opinion had limited impact on a final policy decision, external actors would face strong incentives to shop other venues to pursue their interests, leaving the agency autonomy intact (Chalmers, 2005).

Explaining autonomy, the study illustrates that a narrow focus on the usual legal and institutional suspects risks overlooking the crucial role of (a) ERAs' expertise and (b) their ability to engage in procedural insulation. While these two factors aim to complement- rather than replace-existing explanations, they provide substantive explanatory leverage. Within the existing regulatory framework, the substantive expertise of ERAs seems sufficient to explain the high autonomy from the Commission. Despite the close procedural oversight by the Commission, the substantive information asymmetries guard the decision-making of ERAs from their political principal. In line with delegation theory (asserting E1a), the Commission thus lacks the expert resources to influence the decision-making of ERAs (Majone, 2002). Towards private stakeholders, the asymmetry loses its explanatory leverage. While the expertise of ERAs remains necessary to counter stakeholder arguments (E1b), the strong autonomy of ERAs more centrally relies on the process of procedural insulation (asserting E2): All three ERAs-ECHA due to its young age more than the other two-apply the extensive regulatory framework in a risk-averse manner, and moreover adapt the rules over time to suit their needs. Paraphrasing Kaufman (2001, p. 34), rules ("red tape") indeed serve as a procedural protection.

Political salience affects the way in which ERAs engage in procedural insulation (supporting E3): in areas of low political salience, procedural insulation tends to reflect a process of instrumental problem solving (Boswell, 2008; Rissi \& Sager, 2013). As an externality, raising the procedural hurdle guards the autonomy of ERAs. In areas of high political salience, ERAs act more strategically (Radaelli, 2009). Adding to insights on the utilisation of knowledge, this strategic behaviour also applies to the rulemaking of ERAs (Schrefler, 2010). Even in highly salient areas, ERAs thus remain autonomous from (increasing) external pressures (asserting $E 3 b)$. Findings emphasise that ERAs are not limited to an observer's role; they actively "forge" their autonomy (Carpenter, 2001). Future research could explore in more detail whether this strategic behaviour is also used to pursue organisational goals that potentially undermine the decision-making of ERAs. Findings allow to assess the technocratic claims of ERAs and the legitimacy of expert bodies more generally.

Despite their high degrees of autonomy, all three ERAs face conflicts of interest. Although EFSA was created with a special eye on guarding its autonomy from external influence, it is paradoxically most affected by Col. EFSA's reliance on university researchers, often conducting research funded by industry, provides a potential explanation (Groenleer, 2009). The given findings emphasize the continuous struggle of ERAs to balance the need for external expert knowledge with threat on their autonomy. In any case, the study suggests that Col-although they exist-do not systematically affect decision-making.

The study also locates ERAs in the wider context of EU decision-making. The central role of expertise and the rule-orientation of ERAs form preconditions for effective regulation and give credence to their expertise- 
based legitimacy (Majone, 2009). The highly autonomous ERAs therewith contribute to a "scientisation" of EU decision-making (Flinders, 2004). At the same time, the study emphasises the danger of taking autonomy as an absolute standard to assess agencies: ECHA's evaluation of gallium arsenide shows that industry can effectively delay regulatory action and thus wield major influence on regulatory performance in the EU. EF$S^{\prime}$ 's handling of health claims moreover suggests that ERAs might run the risk of "hitting the [legal] target but missing the [regulatory] point" (Bevan \& Hood, 2006, p. 521). In the end, autonomy proves necessary for high quality expert advice. Yet, it is far from sufficient.

Although the empirical strategy has allowed for a systematic comparison of three major ERAs, the study faces several shortcomings: while the focus on highly "technical" agencies ("extreme cases") forms a precondition for a sensible analysis of the research questions at hand, it also limits the generalization of the findings. The effects of expertise on autonomy might be less pronounced among less "technical" regulatory agencies. Accordingly, conclusions concerning the contribution of ERAs towards the "scientisation" of public decision-making have to be taken with care. Providing valuable insights, this study clearly indicates the necessity of future research on the role of expertise in ERAs and other European (and national) expert bodies: being the central organisational resource, future research should address the role of expertise in non-majoritarian institutions more systematically, addressing its effects on organisational behaviour more generally, and evaluating its importance vis-à-vis other relevant factors.

\section{Acknowledgements}

Since this article materialised from my $\mathrm{PhD}$ research at Bremen International Graduate School of Social Sciences (BIGSSS), I am very grateful for the many insightful remarks on this article by my PhD supervisors Beate Kohler, Arndt Wonka and Claudio Radaelli. In the same breath, I would like to thank my interviewees for sharing their experiences in EU decision-making with me. I am particularly grateful to the institutional support granted by EMA, EFSA, and ECHA, providing me with ample access to their senior staff and scientific experts. I am also indebted to the participants of the EPISTO conference, Cathrine Holst and Ase Gornitzka, as well as the three anonymous reviewers for their critical but constructive remarks on this article.

\section{Conflict of Interests}

The author declares no conflict of interests.

\section{References}

ANH Europe. (2011). EFSA carries on regardless. Re- trieved from http://anh-europe.org/news/efsacarries-on-regardless

Bevan, G., \& Hood, C. (2006). What's measured is what matters: Targets and gaming in the english public health care system. Public Administration, 84(3), 517-538.

Boswell, C. (2008). The political functions of expert knowledge: Knowledge and legitimation in european union immigration policy. Journal of European Public Policy, 15(4), 471-488.

Braun, C. (2012). The captive or the broker? Explaining public agency? Interest group interactions. Governance, 25(2), 291-314.

Brown, M. B. (2009). Science in democracy: Expertise, institutions, and representation. Cambridge and London: MIT Press.

Busuioc, M., \& Groenleer, M. L. P. (2014). The theory and practice of EU agency autonomy and accountability: Early day expectations, today's realities and future perspectives. In M. Everson, C. Monda, \& E. Vos (Eds.), European agencies in between institutions and member states (pp. 175-200). Alphen aan den Rijn: Kluwer Law \& Business.

Busuioc, M. (2013). European agencies: Law and practices of accountability. Oxford: Oxford University Press.

Carpenter, D. P. (2001). The forging of bureaucratic autonomy-Reputation, networks, and policy innovation in executive agencies, 1862-1928. Princeton, Oxford: Princeton University Press.

Carpenter, D. P. (2010). Reputation and power: Organizational image and pharmaceutical regulation at the FDA. Princeton, Oxford: Princeton University Press.

Chalmers, D. (2005). Risk, anxiety and the European mediation of the politics of life. European Law Review, 30(5), 649-674.

Chiti, E. (2013). European agencies' rulemaking: Powers, procedures and assessment. European Law Journal, 19(1), 93-110.

Curtin, D. (2014). Challenging executive dominance in european democracy. The Modern Law Review, 77(1), 1-32.

Davis Cross, M. K. (2012). Rethinking epistemic communities twenty years later. Review of International Studies, 39(1), 137-160.

ECHA. (2011). Policy for managing potential conflicts of interests (No. POL-00XX.01). Helsinki, Finland: Corporate Publication.

EFSA. (2011). Policy on independence and scientific decision-making processes of the European food safety authority. Parma, Italy: EFSA.

Egeberg, M., \& Trondal, J. (2011). EU-level agencies: New executive centre formation or vehicles for national control? Journal of European Public Policy, 18(6), 868-887.

EMA. (2012). European medicines agency policy on the 
handling of conflicts of interests of scientific committee members and experts (No. EMA/513078/ 2010). London, UK: Corporate Publication.

EMA. (2013). Annual report 2012. London, UK: Corporate Publication.

European Court of Auditors. (2012). Management of conflict of interest in selected EU agencies (Special Report 15). Luxemburg: European Court of Auditors.

European Ombudsman. (2013). Handling of a potential conflict of interest arising from a staff member's move to the private sector (Decision No. 0775/ 2010/ANA). Strasbourg: European Ombudsman.

Flinders, M. (2004). Distributed public governance in the European Union. Journal of European Public Policy, 11(3), 520-544.

Gailmard, S. (2002). Expertise, subversion, and bureaucratic discretion. Journal of Law Economics \& Organization, 18(2), 536-555.

Gehring, T., \& Krapohl, S. (2007). Supranational regulatory agencies between independence and control: The EMEA and the authorization of pharmaceuticals in the European single market. Journal of European Public Policy, 14(2), 208-226.

Gormley, W. T. J. (1986). Regulatory issue networks in a federal system. Polity, 18(4), 595-620.

Groenleer, M. L. P. (2009). The autonomy of European Union agencies-A comparative study of institutional development. Delft: Eburon.

Groenleer, M. L. P. (2014). Agency autonomy actually: Managerial strategies, legitimacy, and the early development of the European Union's agencies for drug and food safety regulation. International Public Management Journal, 17(2), 255-292.

Haas, P. M. (1992). Introduction: Epistemic communities and international policy coordination. International Organization, 46(1), 1-35.

Horel, S., \& Corporate Europe Observatory. (2013). Unhappy meal. The European food safety authority's independence problem. Brussels, Belgium: Corporate Europe Observatory.

Jasanoff, S. (1995). Procedural choices in regulatory science. Technology in Society, 17(3), 279-293.

Joerges, C., Ladeur, K., \& Vos, E. (1997). Integration scientific expertise into regulatory decision-making: National traditions and European innovations. Baden-Baden: Nomos Verlagsgesellschaft.

Kaufman, H. (2001). Major players: Bureaucracies in american government. Public Administration Review, 61(1), 18-42.

Lavertu, S., \& Weimer, D. L. (2009). Integrating delegation into the policy theory literature. Policy Studies Journal, 37(1), 93-102.

Lentsch, J., \& Weingart, P. (2011). The politics of scientific advice: Institutional design for quality assurance. Cambridge and New York: Cambridge University Press.
Maggetti, M. (2009). The role of independent regulatory agencies in policy-making: A comparative analysis. Journal of European Public Policy, 16(3), 450470.

Majone, G. (2002). Delegation of regulatory powers in a mixed polity. European Law Journal, 8(3), 319339.

Majone, G. (2009). Europe as the would-be world power. Cambridge and New York: Cambridge University Press.

Moe, T. M. (1995). The politics of structural choice: Toward a theory of public bureaucracy. In O. E. Williamson (Ed.), Organization theory from Chester Barnard to the present and beyond (pp. 116-153). New York: Oxford University Press.

Noordegraaf, M. (2007). From "pure" to "hybrid" professionalism: Present-day professionalism in ambiguous public domains. Administration \& Society, 39(6), 761-785.

Olsen, J. P. (2007). Understanding Institutions and Logics of Appropriateness: Introductory Essay. Centre for European Studies (ARENA Working Paper 13 (07)). Oslo, Norway: ARENA.

Olsen, J. P. (2009). Democratic government, institutional autonomy and the dynamics of change. West European Politics, 32(3), 439-465.

Ossege, C. (forthcoming). European regulatory agencies and EU decision-making. Between expertise and influence. Basingstoke: Palgrave McMillan.

Pollack, M. A. (2015). Theorizing EU policy-making. In H. Wallace, M. A. Pollack, \& A. Young (Eds.), PolicyMaking in the European Union (pp. 13-45). Oxford: Oxford University Press.

PricewaterhouseCoopers (PwC). (2012). Final report on the review of the European chemicals agency. Brussels, Belgium: PricewaterhouseCoopers.

Quaglia, L. (2009). How does expertise influence negotiations in the EU? (UCD Dublin European Institute Working Paper, 09(09)). Dublin: UCD Dublin.

Radaelli, C. M. (1995). The role of knowledge in the policy process. Journal of European Public Policy, 2(2), 159-183.

Radaelli, C. M. (2009). Measuring policy learning: Regulatory impact assessment in europe. Journal of European Public Policy, 16(8), 1145-1164.

Rissi, C., \& Sager, F. (2013). Types of knowledge utilization of regulatory impact assessments: Evidence from Swiss policymaking. Regulation \& Governance, 7(3), 348-364.

Rittberger, B., \& Wonka, A. (2011). Introduction: Agency governance in the European Union. Journal of European Public Policy, 18(6), 780-789.

Sabel, C. F., \& Zeitlin, J. (2008). Learning from difference: The new architecture of experimentalist governance in the EU. European Law Journal, 14(3), 271-327.

Schrefler, L. (2010). The usage of scientific knowledge 
by independent regulatory agencies. Governance, 23(2), 309-330.

Shapiro, S., \& Guston, D. (2007). Procedural control of the bureaucracy, peer review, and episternic drift. Journal of Public Administration Research and Theory, 17(4), 535-551.

Tversky, A., \& Kahneman, D. (1992). Advances in prospect theory: Cumulative representation of uncertainty. Journal of Risk and Uncertainty, 5(4), 297323.

Vestlund, N. M. (2014). Exploring EU commissionagency relationship: Partnership or parenthood? In
M. Bauer \& J. Trondal (Eds.), The palgrave handbook of the european administrative system. Basingstoke: Palgrave Mcmillan.

Vibert, F. (2007). The rise of the unelected: Democracy and the new separation of powers. Cambridge: Cambridge University Press.

Vos, E. (2014). European agencies and the composite EU executive. In M. Everson, C. Monda, \& E. Vos (Eds.), EU agencies in between institutions and member states (European Monographs, No. 85 ed., pp. 11-47). Alphen aan den Rijn: Kluwer Law International.

\section{About the Author}

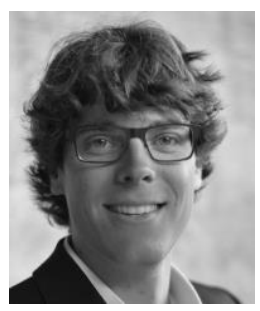

\section{Dr. Christoph Ossege}

Christoph Ossege works as a Senior Policy Officer in the "SSM Policy and Coordination Unit" at the German Federal Financial Supervisory Authority. He obtained a PhD at Bremen International Graduate School of Social Sciences (BIGSSS), studying the importance of expert knowledge and autonomy for the decision-making quality and legitimacy of European Regulatory Agencies (ERAs). Christoph also held positions as honorary university fellow at the Centre for European Governance, Exeter University, and as a visiting researcher at ARENA-Centre for European Studies at Oslo University. 